\title{
A solution for funding the development of technology in oilwell drilling
}

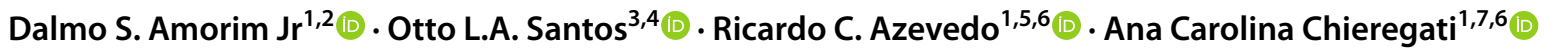

Received: 25 April 2020 / Accepted: 20 October 2020 / Published online: 3 November 2020

(c) The Author(s) 2020

\begin{abstract}
This article proposes a novel methodology to solve an existing gap in benchmark definition by the adoption of statistically defined benchmarks as references to test products or technical procedures. In a win-win partnership, remuneration is made upon realistic bases of comparison being proportional to existing risks. However, establishing values for benchmarks is rarely unanimous if asked to different persons involved in drilling analysis. Conventional benchmarking, which enhances few results and leaves aside poor operational performances, produces references that do not properly represent the geological environment. Nonetheless, when testing new products, it serves as reference to remunerate suppliers. The review of an optimization program, which resulted in a world record of drilling rate of penetration, reveals the financial magnitude of the savings produced, proposing the method discussed as a reliable solution to the development of technology.
\end{abstract}

Keywords Technical limits $\cdot$ Benchmark $\cdot$ Drilling economics $\cdot$ Amorim curve

\section{Introduction}

One of the primeval objectives of an optimization process is to produce cost reduction in future events. In this sense, marketing is a valuable tool in disclosing new technologies. By generating a high expectation to products or procedures under development, clients might be templated to test them. However, as financial losses are among the potential results

Dalmo S. Amorim Jr

dalmo.amorim@gmail.com

1 Mineral Sciences, USP - University of São Paulo, São Paulo, Brazil

2 Petroleum Engineering, Department of Petroleum and Mining Engineering, USP - University of São Paulo, São Paulo, Brazil

3 Petroleum Engineering, Colorado School of Mines, Golden, CO, USA

4 Petroleum Engineering, Louisiana State University, Baton Rouge, LA, USA

5 Petroleum Engineering, University of Stavanger, Stavanger, Norway

6 Mining and Petroleum Engineering Department, USP - University of São Paulo, São Paulo, Brazil

7 Petroleum Engineering, Aalborg University, Aalborg Øst, Denmark of testing new products, reliable benchmarks are mandatory to estimate the true financial impact of the results produced by testing.

New technologies are offered at higher prices, compensating long periods of development and a risk of not beating performances arbitrated by the operator. On the other side, operators adopt a conservative posture, paying the developer upon the achievement of best-in-class performances. Both act protecting themselves from financial losses instead of providing efforts to develop reliable solutions for the existing limits.

Conventional references of drilling performances are the result of averages of longer lengths drilled, selected among bit runs with extended operational hours, a process repeated for all the sections of a well. However, such references are rarely unanimous when asked to different persons involved in drilling analyses.

As formations become more compact when vertical depths increase, benchmarks based on averages embed risk of not representing the geological environment. Matching objectives of a marketing department or representing personal points of view, the current method is not adequate to disclose operational aspects.

The article proposes a methodology that uses statistically defined benchmarks as reference, replacing the vague estimations based on averaged performances. A world record 
of drilling rate of penetration (ROP) is used to demonstrate how savings can be used to finance research and development $(R \& D)$ in a more reliable basis.

\section{Performance evaluation in drilling activities}

KPIs, or Key Performance Indicators, are drivers useful for replicating the 'best-in-class' performances (Gillen 2008). KPIs of insufficient complexity, or referenced in a wrong approach, might conduct management to seek for unreachable targets, sub-estimate the risks and do not develop the necessary sustainable strategies to reduce operational costs (Kaplan and Cooper 1998).

Benchmark is an expected performance, which represents a useful reference in project planning to reference projections with previous results (Stapenhurst 2009). A topology containing the proper benchmarks will represent the environment and allow identifying drivers and layers of parameters that can lead to excellence (Cun Qing and Zheng 2012). In this sense, the subject raises significant questions:

- Does a performance proposed by a drilling operator, averaged from a handful of longer runs in a field, properly characterize a topology representative enough to define valid challenges for technical tests?

- How many performances, among a database of offset records, should be used to generate a reliable reference, properly representing a geological environment (Simmons 1986)?

A technical limit is the best performance in an environment, achieved using existing resources at its maximum efficiency.

A world record is the highest technical limit within a category, established in a progressive, unique and well-accepted database. Generally, world records in drilling operations are classified in three categories: the longest drilled length by a single bit run, the highest rate of penetration, and the cumulative drilled length per a bit, adding up numerous world records in function of the bit diameter and technology. Validated and published by journals, like Hart's E\&P (Weeden 2016), published case studies discussing such records are, however, surprisingly rare in scientific journals.

\section{Common paths of optimization processes}

Testing new resources requires reliable references to estimate the true impact of results achieved. When a new set of resources produces improvements, progresses in performance are expected.

As the development of new technologies is a riskbased activity, typical barriers are interposed, like resistance from managers, high costs of risk management and difficulties in managing risk sceneries (Dandage et al. 2017). Most common paths for testing new technologies:

- Purchasing and implementing-a conventional mode where a third party develops products or more effective processes, embedding the investments and time spent in the price of the product.

- R\&D-research and development are typical paths of the PDCA cycle (Garcia and Calantone 2002); requiring local investments, the process embeds risks of investing without enough financial return.

- Remunerating tests based on risk-a midterm for the development of technologies with suppliers, paying bonuses upon increased performances.

The economical impact (EI) provided by the tests must be measurable and change depending on the references adopted. As pointed earlier, the absence of a well-accepted method to define a benchmark is an actual obstacle.

\section{Methodology and data}

This section presents a solution for drilling oilwells, with statistical regressions replacing conventional benchmarks created by arbitrary selection of lengths drilled or rotating hours.

It discusses two methods of providing benchmarks: the approach shown in Table 1, where an average of randomly selected performances defines the benchmark, and the novel method proposed in section "Statistical aspects of drilling performances".

\section{Economical aspects of drilling performances}

Analyzing performances is a typical approach of engineering in drilling operations. Drilling economics, not drilling performances, should first subsidize well planning and analyses of performances.

Increased expenditures are compensated by additional lengths drilled without tripping to change the bit, reusing the bit in following wells, high rates of penetration, improvements in drilling efficiency and by reduction in lost time.

Bits manufactured with improved technology, run with special tools and using existing resources at a high level of efficiency should produce reduced drilling costs, if recommended parameters are respected to avoid accidents (Amorim et al. 2020).

Cost in drilling operations uses a traditional formula, expressed by Eq. (1): 
Table 116 longest runs in the 14.1/2" section in Cantarell Field

\begin{tabular}{lllllll}
\hline Bit Type & Out & Meters & HR & ROP & CM & Year \\
\hline M0719 & 2471 & 1671 & 99.00 & 16.9 & 1226 & 2007 \\
M0719 & 2285 & 1465 & 111.47 & 13.1 & 1569 & 2007 \\
S0616 & 2138 & 1338 & 29.08 & 46.0 & 486 & 2007 \\
M0719 & 2126 & 1321 & 40.90 & 32.3 & 671 & 2008 \\
S0816 & 2075 & 1273 & 39.01 & 32.6 & 666 & 2007 \\
S0816 & 2359 & 1252 & 58.47 & 21.4 & 1003 & 2007 \\
S0816 & 2033 & 1224 & 83.04 & 14.7 & 1413 & 2007 \\
M0719 & 2020 & 1210 & 62.20 & 19.5 & 1085 & 2007 \\
S0816 & 1916 & 1101 & 65.13 & 16.9 & 1246 & 2007 \\
S0816 & 1900 & 1080 & 31.58 & 34.2 & 649 & 2007 \\
M0719 & 1880 & 1075 & 46.21 & 23.3 & 923 & 2007 \\
S0816 & 1734 & 934 & 18.01 & 51.9 & 458 & 2006 \\
S0616 & 1702 & 780 & 27.23 & 28.6 & 796 & 2008 \\
S0816 & 2476 & 742 & 41.23 & 18.0 & 1278 & 2006 \\
S0816 & 2318 & 418 & 39.27 & 10.6 & 2200 & 2007 \\
115 & 2905 & 377 & 90.17 & 4.2 & 5239 & 2002 \\
Average & - & 1079 & 55.13 & 19.6 & 1100 & - \\
\hline
\end{tabular}

Data source: PEMEX
$\mathrm{CM}=\frac{(\mathrm{CB}+\mathrm{CH} \times(\mathrm{TT}+\mathrm{HR}))}{\mathrm{MD}}$

- $\mathrm{CM}-$ cost per meter at the depth that the bit ended the run (US\$/m)

- $\mathrm{CB}$ - cost of the bit (US\$)

- $\mathrm{CH}$-sum of rental costs per hour, as rig and special tools (US\$/h)

- TT-time spent in a round trip to replace the bit (h)

- HR-time spent at the drilling operation (h)

- MD—length drilled by the bit (m)

\section{Statistical aspects of drilling performances}

The solution presented in this article, grounded on the line of research of one of the article authors, states that every drilling performance must be included in the dataset of the field to produce a reliable representation of the geological environment (Amorim et al. 2019). The result is an exponential regression, expressed by Eq. (2) (Lapeyrose 2002):

$\mathrm{CM}=k_{1} \times e^{k_{2} \times D}$

Generated by Excel, the regression represents the benchmark of drilling costs at any depth in the geological area of the database. The formula is useful to anticipate drilling costs during well planning by replacing $\boldsymbol{D}$ (Depth Out) in Eq. (2) for a desired planned bit depth out.

Factors $\boldsymbol{k}_{1}$ and $\boldsymbol{k}_{\mathbf{2}}$ measure how efficiently existing techniques and available resources are used to overcome the physical and geological aspects inherent of the data sample. As the database grows, it will slightly produce more definitive factors $\boldsymbol{k}_{\mathbf{1}}$ and $\boldsymbol{k}_{\mathbf{2}}$ for that area.

Because variable $\boldsymbol{D}$ is in the exponent, $\boldsymbol{C M}$ will change rapidly as depth increases, affected by $\boldsymbol{k}_{\mathbf{1}}$ combined with the magnitude of $\boldsymbol{k}_{\mathbf{2}}$ (Devore 2010).

The Amorim curve is the graphical interpretation of Eq. (1), shown in Fig. 1:

- A dot sitting on the Amorim curve is the benchmark at that depth

- Dots below the curve are better performances than the benchmark of the field at that depth

- Dots above the curve are worse performances than the benchmark of the field at that depth

- Lowest values in a depth range are the technical limits in that fraction of the geological environment

- High dots are unsuccessful runs and represent opportunities for improvements

- Reported changes in time periods for $\boldsymbol{k}_{\mathbf{1}}, \boldsymbol{k}_{\mathbf{2}}$ and $\boldsymbol{C M}$ validate the technical evolution of a drilling campaign

- Identifying bit runs by $\boldsymbol{C M} \times$ Depth Out allows replicating, or avoiding, the resources used

Filtering the dataset produces refined analyses, revealing how drilling costs are affected by technology of bits, number of blades, diameter of the section, usage of roller reamers and other operational flags. The results will be expressed by new values of $\boldsymbol{k}_{\mathbf{1}}$ and $\boldsymbol{k}_{2}$, more adequate to support a Project Engineer in well planning. 
Fig. 1 Dispersion of CM versus depth out. Source: the authors

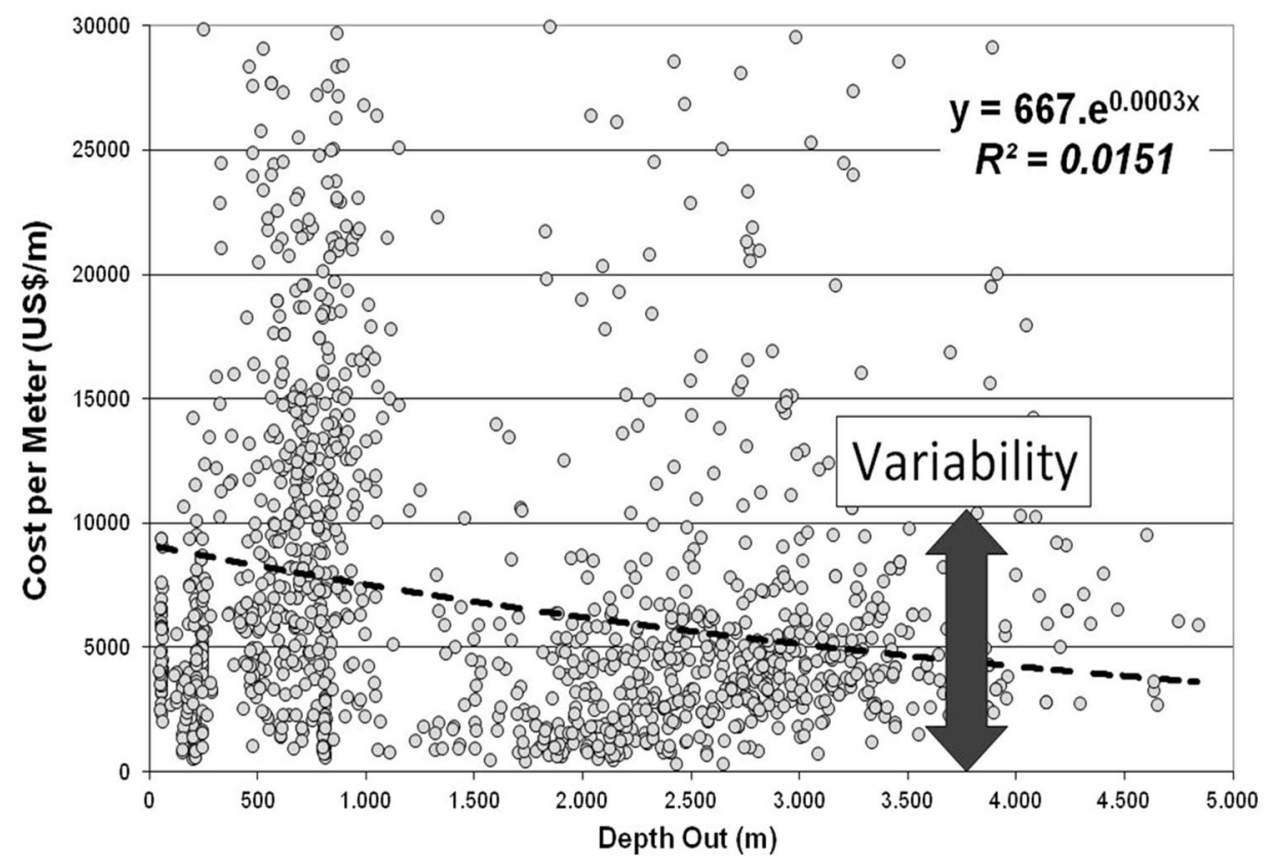

\section{Economical aspects of drilling performances}

The methodology results in anticipating the cost per meter at any segment of the well trajectory, achieved by integrating Eq. (2) for a given interval:

CostInterval $=\int_{\text {DepthIn }}^{\text {DepthOut }} k_{1} \times e^{k_{2} \times D}$

CostInterval $=k_{1} \times\left\{\left(e^{k_{2} \times \text { Depth }_{\text {out }}}\right)-\left(e^{k_{2} \times \text { Depth }_{\text {in }}}\right)\right\} \div k_{2}$

Equation (4) is useful in anticipating CAPEX in well planning, done by calculating the cost of drilling a section, or even the entire trajectory, by replacing Depth In (D1) and Depth Out (D2) of the interval.

\section{Risk estimation}

Exponential regressions produce an associated factor $\boldsymbol{R}^{\mathbf{2}}$, relevant for the process as it represents the variability of existing samples in a database in relation to the benchmark. In the Amorim curve methodology, emphasized by the vector in Fig. 1, variability is an estimation of risk at a surrounding depth range.

A large value of $\boldsymbol{R}^{2}$ expresses quite spread-out dots about the true regression line, whereas when $\boldsymbol{R}^{2}$ is small, the observed points will tend to fall very close to the true line (Devore 2010). Under an operational point of view,
$\boldsymbol{R}^{2}$ represents the risk of drilling in the geological area of the data sample using the same resources.

The risk is visually expressed by the vertical spreading of dots, seen in Fig. 1.

- Values of $\boldsymbol{R}^{2}$ closer to 0 reflect more homogeneous formations, consistent drilling practices or great number of samples in the database.

- Values of $\boldsymbol{R}^{2}$ closer to 1 reflect geological inconsistencies, alternating poor and good drilling practices, short runs mixed with long performances and uneven levels of technologies used through time.

\section{Economical impact}

When a new set of resources produces a relevant performance, discrepancies in cost are noted.

The economical impact (EI), expressed by Eq. (5), is the difference between the benchmark of the field and the actual cost to drill, measured at the depth out using new resources under test:

$\mathrm{EI}=\mathrm{MD} \times\left(\mathrm{CM}_{\text {benchmark }}-\mathrm{CM}_{\text {new }}\right)$

$\mathrm{EI}=\mathrm{MD} \times\left\{\mathrm{CM}_{\text {benchmark }}-[(\mathrm{CB}+\mathrm{CH} \times(\mathrm{TT}+\mathrm{HR})) \div \mathrm{MD}]_{\text {new }}\right\}$

Actions that can result in positive economical impacts become evident by analyzing Eq. (6): 
- Longer-bit runs increase EI if producing an equivalent ROP

- Less trip time in an entire section, to be seen in section "Strategy", is another benefit of longer bit runs

- Higher ROP represents gain in rig hours (HR), if producing equivalent or higher length drilled

- New tools can result in a combination of gains described above, however affecting $\mathrm{CH}$

- Procedures that increase the efficiency of drilling processes can produce remarkable EI without new physical resources, like processes of mitigation of drilling vibrations or reduction in drilling friction.

\section{Remunerating partners}

The gap between values of reference and results achieved validates the test results. The negotiation between partners is now restricted to defining a percentage upon potential savings or losses produced. Notice that the economical impact can also be negative or null when tests do not produce gain in efficiency.

A fair solution for remuneration is applying the same percentage of bonus to discount the price quoted by the supplier, limited to its value. Higher bonuses mean higher responsibility in providing the best solution. Benefits:

- Shared savings will help partners interested in further improvements of their products and procedures, producing in a win-win partnership

- Operators might finance optimization projects by offering shares like 40-60\%

- A partner will implement the best resources and monitor the operations, willing to achieve a technical record in every operation. In addition, refinements can be produced by further improvements to products or processes tested.

It must be said that the economical impact of upcoming tests will rely on new factors $k_{1}$ and $k_{2}$, as the database will be updated after the end of the wells, when lessons learned are produced.

\section{Results}

\section{Case study of an optimization process in Cantarell Field, Mexico}

Scientific papers presented in congresses usually report successful achievements where suppliers and clients are involved. Rare are scientific articles analyzing unsuccessful performances and the environment of world records in Drilling Engineering. A case study presented at LACPEC - SPE Latin American Caribbean Petroleum Conference (Amorim et al. 2012) is reviewed under two economical visions: the traditional performance analysis, presented in section "Analysis of the 14.1/2" section in Cantarell Field, MX", and the novel topology presented in section "Analysis of the achievements under an economical point of view".

Cantarell Field, discovered in 1971, is one of seven giant offshore oilfields explored by PEMEX (the Mexican stateowned oil company) at Campeche Bay, Gulf of Mexico (Rosellón and Zenón 2012). In the 1980s, it was the largest offshore development project in the world and the most important source of petroleum resources of Mexico (Offshore Technology), with proven reserves peaking 50 billion barrels (Walzel 2019).

In 2009, a diagnostic of drilling performances used a robust dataset of 958 offset runs, provided by PEMEX, to search for potential improvements. With long runs and high rates of penetration, achieved throughout decades, little space seemed to exist for overcoming any of the existing technical limits.

\section{Analysis of the $14.1 / 2$ " section in Cantarell Field, MX}

Table 1 contains the performances of the 16 longest runs in $14.1 / 2$ ". The PDC bits achieved 15 of the longest runs, followed by one rollercone bit.

The nomenclature $\mathbf{1 1 5}$ for rollercone bits used in Table 1 stands for IADC 115 bits (McGehee et al. 1992). For PDC bits, TBBCC replaces an obsolete IADC standard for fixed cutter bits (Brandon et al. 1992), where T stands for body material (M for matrix, $\mathrm{S}$ for steel), BB for number of blades and $\mathbf{C C}$ for the size of the main cutter ( $\mathrm{mm})$.

Analysis of graphs shown in Figs. 2 and 3:

- Two longest runs used seven blade bits, 19-mm PDC cutters, performing lower ROP than the overall average.

- Bits with 16-mm PDC cutters achieved the four highest ROP's of the sample.

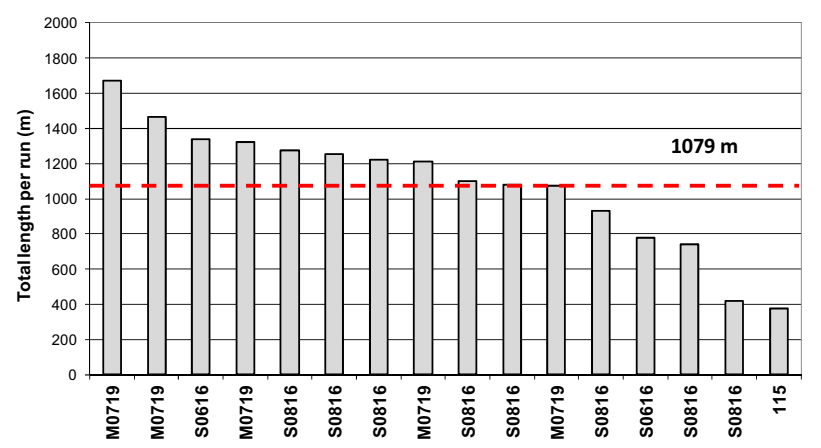

Fig. 2 Extension drilled and bit type of the 16 longest runs in Cantarell Field, as of 2009. Source: the authors 


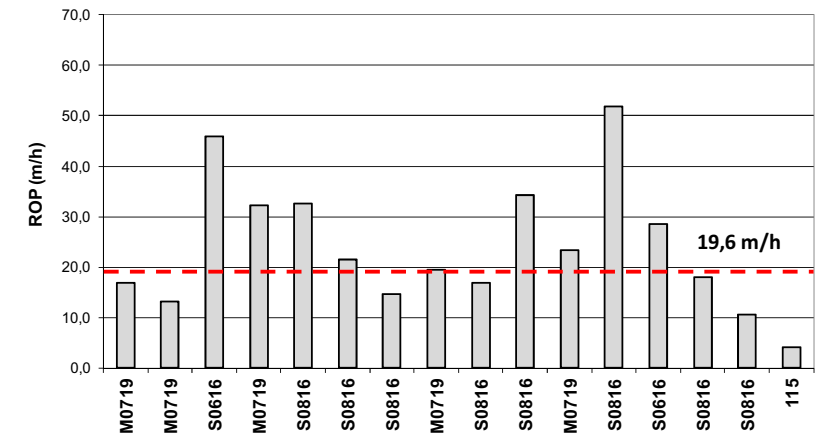

Fig. 3 Equivalent ROP of the 16 longest runs in Cantarell, as of 2009. Source: the authors

- The rollercone bit achieved $377 \mathrm{~m} / 90.2 \mathrm{~h}$, ROP of $4.2 \mathrm{~m} / \mathrm{h}$, slower than any other typical performance.

Based on the analysis presented, a test would be valid if overcoming the averaged performances of the sample in Table 1: $1079 \mathrm{~m} / 55 \mathrm{~h}$, performing $19.6 \mathrm{~m} / \mathrm{h}$. A target was proposed to PEMEX: drill $1800 \mathrm{~m} / 72 \mathrm{~h}$, yielding an average ROP of $25.0 \mathrm{~m} / \mathrm{h}$. If achieved, it would represent a new technical limit in Cantarell Field.

\section{Challenges to overcome}

Sources of inefficiency in directional drilling result in considerable variation of loads delivered to the bit to drill (Fazaelizadeh 2013). Numerous models establish the relationship between bit RPM and the rate of penetration (Yavari et al. 2018), and between string RPM and the amount of energy wasted by resonance and by friction with the walls (Cui et al. 2015).

Friction misuses and dissipates the energy supplied by the drilling system (Rahmani et al. 2019). Low rotational speed of the drill string is desirable, avoiding consuming shares of the energy devoted solely to drilling a well (Christoforou and Yigit 1997). However, as low rotational speed results in low ROP, additional speed solely to the bit is necessary to achieve the proposed performances (Arild 2014).

\section{Strategy}

To increase drilling efficiency, the solution was providing low RPM to the drill string, high RPM to the bit and minimum drilling vibrations while using the highest parameters within available resources. The proposal relied on achieving high drilling efficiency and low shock levels, based at a unique combination of factors:
- Extend the life of bit and drilling tools by using finite element analysis (FEA) to avoid preidentified string harmonics (Etaje 2018), selecting parameters at 'out-ofresonance' ranges (Menand and Mills 2017);

- Minimize dissipation of energy to the environment (Lapeyrose 2002) by reducing rotational speed of the drill string to minimize friction with the walls;

- Deliver high RPM at the bit by using a downhole motor (PDM) positioned above the directional tool (Toumi et al. 2017);

- Supervise in real-time key elements as impact levels and cost per meter and MSE (Berg and Tveit 2016), adjusting parameters as needed during the drilling operations;

- Drill well $2060 \mathrm{H}$ from casing shoe to the total depth, using a single 6-blade bit with 16-mm premium PDC cutters, torque control elements and a low friction gauge; use a bit specially designed for the push-the-bit rotary steerable system (RSS) tool;

- In well $490 \mathrm{H}$, a second test would be performed, being an eccentric tool added to the BHA to increment the mitigation of lateral vibrations and improve even more the ROP (Greenhill and Cornejo 1995);

- Validate the methodology by post-analysis, recording vibrations and impacts with a pair of downhole acceleration sensors placed close to the bit, and another pair installed higher in the BHA;

- Pull the bit in the best moment: at the minimum cost per meter or at the end of the section;

- Use adequate hydraulics to produce cleaning efficiency at very high rates of penetration.

\section{Results in Cantarell 2060H: a world record}

In well Cantarell $2060 \mathrm{H}$, a 'J' trajectory was built in the $14.12^{\prime \prime}$ section, from vertical to $44^{\circ}$, with the help of a pushthe-bit rotary steerable system. A downhole motor, necessary to reduce the fluctuation of drilling torque caused by friction of the rotating drill pipe with walls, provided additional rotational speed necessary at the bit.

The bit cut cement and shoe and drilled $1822 \mathrm{~m}$ in 27.50 rotating hours, achieving a ROP of $66.3 \mathrm{~m} / \mathrm{h}$.

The directional tool company claimed to having performed the longest run with this BHA design, while PEMEX celebrated the following achievements:

- Longest single run in GOM

- Longest length drilled in 24 drilling hours in GOM

- A new world record of rate of penetration for $14.12^{\prime \prime}$ PDC bits, not yet overcome in 2020

For the development of this article, the database of Cantarell Field was updated in 2019, being noticed that a 12.1/4" PDC bit drilled $2525 \mathrm{~m}$, yielding a ROP of $16.9 \mathrm{~m} / \mathrm{h}$. This 
Table 2 Performance of $14.12^{\prime \prime}$ bits of the optimization project

\begin{tabular}{lllllll}
\hline Bit type & Out & Meters & HR & ROP & CM & Year \\
\hline S0616 & 2647 & 1822 & 27.45 & 66.4 & 339 & 2009 \\
S0616 & 1570 & 740 & 14.78 & 50.1 & 494 & 2009 \\
Average & - & 1281 & 21.12 & 60.7 & 384 & - \\
\hline
\end{tabular}

Source: the authors

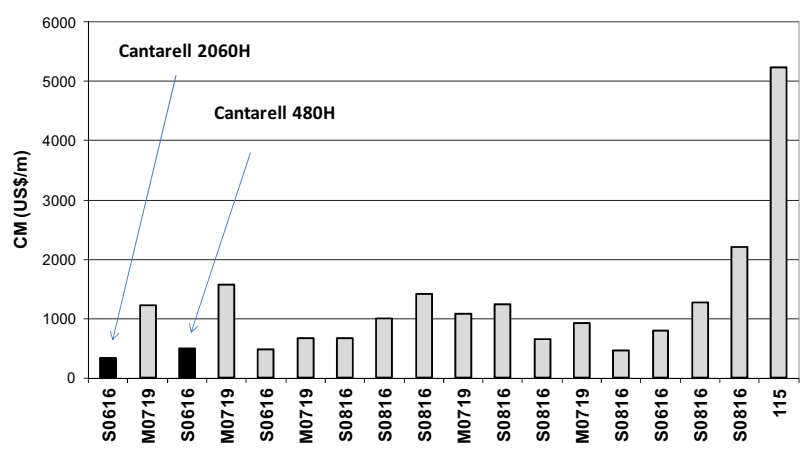

Fig. 4 CM for Cantarell Field, as of 2019. Source: the authors

length represents now the technical limit for a longest single run in the field.

\section{Results in Cantarell 490H: improved drilling stability}

Besides an identical strategy used in well $2060 \mathrm{H}$, in the second well an eccentric tool was added close to the bit to increase lateral stability to the BHA. Lower levels of wasted energy produced a remarkable average $R O P$ above $100 \mathrm{~m} / \mathrm{h}$, which would result in a new World Record at the end the section.

However, the technical limits were no longer determined by the drilling operation but by the drilling system. Largely surpassing the capacity of the rig to deal with cuttings arising at surface, the optimization process was halted and ROP was controlled. The rest of the section was drilled with limited parameters.

The bit completed $740 \mathrm{~m}$ in $14.8 \mathrm{~h}$, still yielding an excellent ROP of $50.1 \mathrm{~m} / \mathrm{h}$.

\section{Economical impact of the optimization project}

Performances achieved in the project, seen in Table 2:

Drilling costs achieved in the project, seen in Fig. 4:

Economical Impact of the project:

$$
\begin{aligned}
& \mathrm{EI}=\mathrm{MD} \times\left(\mathrm{CM}_{\text {benchmark }}-\mathrm{CM}_{\text {new }}\right) \\
& \mathrm{EI}=2562 \times(1100-384)=\mathrm{US} \$ 1,834,885
\end{aligned}
$$

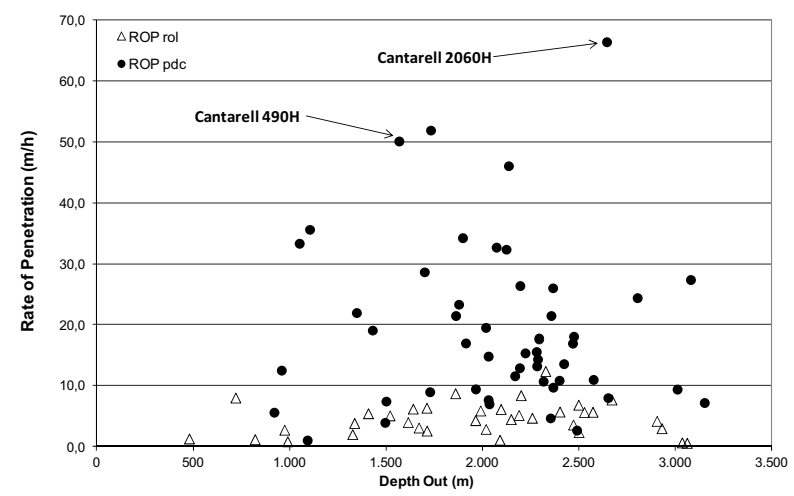

Fig. 5 ROP in $14.1 / 2$ " in Cantarell $\times$ depth out $\times$ bit technology, as of 2019. Source: the authors

\section{Discussion of results}

The economical impact achieved in the optimization project in Cantarell Field, reviewed in section "Results", was based at the performances seen in Table 1, arbitrarily selected among the best results achieved in about three decades.

This section reviews the results by presenting drilling performances in function of well depth, producing a more reliable topology. The Amorim curve amplifies the performance analysis, reporting cost per meter versus well depth.

This novel approach demonstrates that by adopting statistical benchmarks as reference, a more reliable magnitude of savings is revealed. With an economical impact based on all performances in a geological area, and variable according to the well depth, the method is a source of resources that can finance $R \& D$ in drilling operations.

\section{Achievements under an operational point of view versus well depth}

Analysis of Fig. 5:

- PDC bits produce higher ROPs than rollercone bits at most depth ranges

- The technical limit of ROP in the field was achieved in well $2060 \mathrm{H}$ 
- Despite drilling with controlled ROP in well $490 \mathrm{H}$, a noticeable performance was produced

Presenting drilling performances of every performance versus well depth generates a better solid vision of the environment than common tables and charts of averaged performances, shown in section "Results".

Analysis of Fig. 6:

- A slope indicates that most bits start drilling from casing shoe at $900 \mathrm{~m}$ of depth

- PDC bits perform the longest runs of the field

- Rollercone bits drill at most $500 \mathrm{~m}$ despite the well depth

\section{Economical aspects of drilling performances in Cantarell Field}

The Amorim curve for Cantarell Field, shown in Fig. 1, is the result of the statistical regression of 1481 offset bit runs, after updating the database in 2019:

$\mathrm{CM}=667 \times e^{0.0003 \times \text { Depth Out }}, R^{2}=0.0151$

Equation (7) represents the benchmark of drilling performances in that field.

\section{Analysis of the achievements under an economical point of view}

Filtering the database for $14.12^{\prime \prime}$ and for bit technologies produces two specific Amorim curves, expressed in Eqs. (8) and (9) and plotted in Figs. 7 and 8. For clarity purposes, vertical scales are limited to US $\$ 20000 / \mathrm{m}$ due to an expressive dispersion of results.

Analysis of Fig. 7:

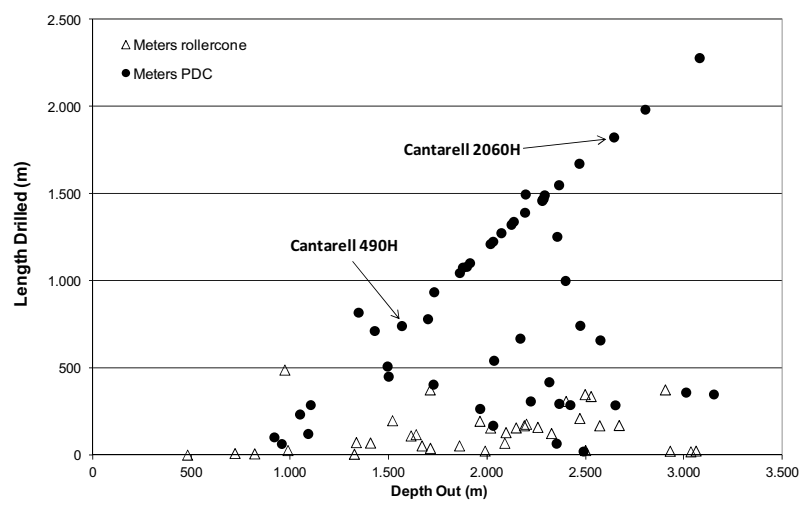

Fig. 6 Length drilled in $14.12^{\prime \prime}$ in Cantarell $\times$ depth out $\times$ bit types, as of 2019. Source: the authors

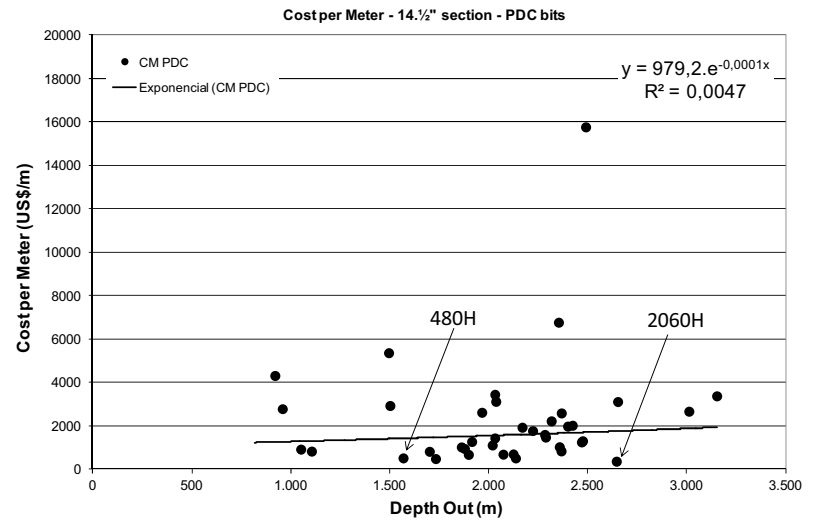

Fig. $7 \mathrm{CM} \times$ Depth Out for the $14.12^{\prime \prime}$ section of PDC bits, as of 2019. Source: the authors

- The Amorim curve for PDC bits is entirely under US $\$ 2000 / \mathrm{m}$

$\mathrm{CM}_{\mathrm{PDC}}=979.2 \times e^{-0.0001 \times \text { Depth Out }}, R^{2}=0.047$

- The performance achieved in well $2060 \mathrm{H}$ represents the technical economical limit of the section

Analysis of Fig. 8:

- The Amorim curve for rollercone bits is entirely above US $\$ 6000 / \mathrm{m}$, meaning that higher costs are expected at any depth of the section

$\mathrm{CM}_{\mathrm{Rol}}=9.6 \times e^{0.005 \times \text { Depth Out }}, R^{2}=0.1395$

- Factor $\boldsymbol{R}^{2}$ for rollercone bits (0.1395), compared to $\boldsymbol{R}^{2}$ for PDC bits (0.047), reflects a higher drilling risk and less chance of achieving performances sitting at the benchmark curve;

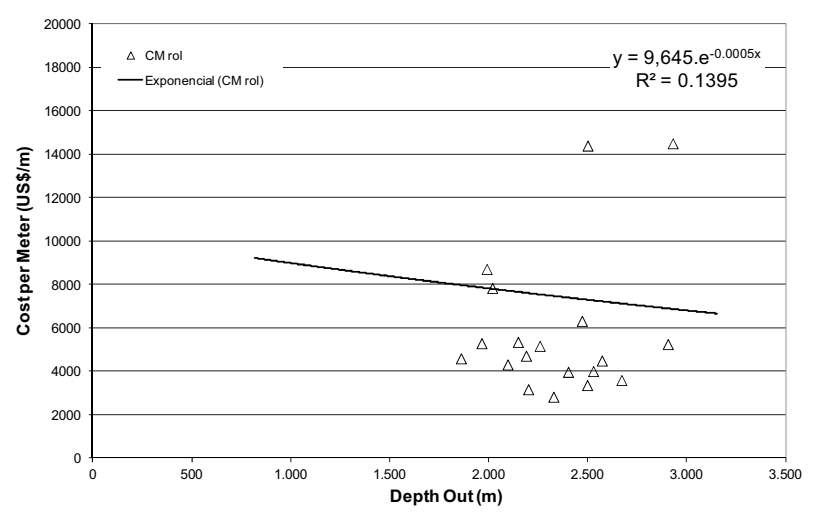

Fig. $8 \mathrm{CM} \times$ Depth Out for the $14.1 / 2^{\prime \prime}$ section of rollercone bits, as of 2019. Source: the authors 


\section{Economical impact}

Based at the figures presented, the optimization project produced the following results:

- Depth out in well $2060 \mathrm{H}=2647 \mathrm{~m}$; length drilled $=1822 \mathrm{~m} ; \mathrm{CM}_{2060 \mathrm{H}}=339 \$ / \mathrm{m}$.

$$
\mathrm{EI}_{2060 H}=\left(667 \times e^{0.0003 \times 2647}-339\right) \times 1822=\mathrm{US} \$ 2,071,073
$$

- Depth out in well $490 \mathrm{H}=1570 \mathrm{~m}$; length drilled $=740 \mathrm{~m} ; \mathrm{CM}_{490 \mathrm{H}}=494 \$ / \mathrm{m}$

$$
\text { Savings }_{490 H}=\left(667 \times e^{0.0003 \times 1570}-494\right) \times 1570=\mathrm{US} \$ 901,594
$$

Total savings of the project: US $\$ 2,071,073+$ US $\$ 901$, $594=$ US $\$ 2,972,668$.

\section{Financing research and development with savings produced}

The economical impact of the project, presented in sections "Economical impact of the optimization project" and "Economical impact" under different approaches, measures the benefits of the project in relation to the current practices in the field.

However, the method described in section "Economical impact", based at statistically defined benchmarks, produces a reliable measure of the economical impact regarding the value of the length drilled, time and resources spent and depth out. Sharing measurable potential savings can incentive partners to use their best available resources in a $R \& D$ project, in opposition to traditional methods of purchasing the lowest priced products.

Regarding the economical impact produced, a purchasing system using this method to bid percentages of share between suppliers and operators has the foundations to build a win-win relationship.

\section{Conclusions and recommendations}

Marketing actions are effective ways for disclosing new technologies, historically done by enhancing the best in class runs of a supplier, especially useful when insufficient offset information is available. Using tables and equivalent charts as shown in section "Results", this approach is simple to build and to interpret.

When poor results or premium performances of competitors are not considered, the results present an unreliable topology of the environment, underestimating the risks of an enterprise to drill a well.
The economical impact provided by the methodology of the Amorim curve reduces the influence of marketing and dependency on expertise of project engineers, opening way for novel solutions demonstrated in section "Economical impact".

The performances of the optimization project achieved in Cantarell Field, reviewed in this article and validated under a wider approach, express the magnitude of the resulting savings and subsidize similar approaches in other geological areas.

According to the authors' visions, marketing actions that enhance performances using the presented methodologies will provide a reliable and unbeatable argument to clients.

Acknowledgements Our acknowledgements to Jennifer Presley, Henry Tinne and Hart's E\&P Magazine, for the extensive database about World Records in drilling oilwells, and to PEMEX for the Bit Records and performances in Cantarell Field.

Authors' contributions Not applicable.

Funding The efforts in publishing this article are to achieve a doctoral degree in petroleum engineering by the corresponding author, without external sources of financing.

Availability of data and material The present case study reviews a published article using information provided by PEMEX, updated in 2019. The corresponding author prepared and produced all charts and tables of this article.

\section{Compliance with ethical standards}

Conflict of interest None, no brands or disputes.

Code availability Not applicable.

Open Access This article is licensed under a Creative Commons Attribution 4.0 International License, which permits use, sharing, adaptation, distribution and reproduction in any medium or format, as long as you give appropriate credit to the original author(s) and the source, provide a link to the Creative Commons licence, and indicate if changes were made. The images or other third party material in this article are included in the article's Creative Commons licence, unless indicated otherwise in a credit line to the material. If material is not included in the article's Creative Commons licence and your intended use is not permitted by statutory regulation or exceeds the permitted use, you will need to obtain permission directly from the copyright holder. To view a copy of this licence, visit http://creativecommons.org/licenses/by/4.0/.

\section{References}

Amorim DS Jr, Hanley C, Leite DJ (2012) Parameter definition using vibration prediction software leads to significant drilling performance improvements. In: SPE (ed) Latin American and Caribbean petroleum engineering conference. Society of Petroleum Engineers, Ciudad de México, p 9 
Amorim DS Jr, Santos OL, Azevedo RC (2019) A statistical solution for cost estimation in oil well drilling. REM Int Eng J 72(4):675683. https://doi.org/10.1590/0370-44672018720183

Amorim DS Jr, Santos OL, Azevedo RC (2020) New industry standards to increase the reliability of drilling operations. Holos, p 14

Arild S (2014) Annular frictional pressure losses during drilling - predicting the effect of drillstring rotation. J Energy Resour Technol 136(3):5

Berg PV, Tveit ØS (2016) Model for evaluating drilling efficiency based on the concept of Mechanical Specific Energy. Norwegian University of Science and Technology, Department of Petroleum Engineering and Applied Geophysics, NTNU, Trondheim, Norway

Brandon BD et al (1992) Development of a new IADC fixed cutter drill bit classification system. In: IADC/SPE (ed) 1992 IADC/SPE drilling conference, IADC/SPE 23940. New Orleans, pp 841-848

Christoforou AP, Yigit AS (1997) Dynamic modelling of rotating drillstrings with borehole interactions. J Sound Vib 206(2):243-260

Cui M, Wang HG, Zhao JY, Cui L, Chen ZX (2015) Optimizating drilling operating parameters with real-time surveillance and mitigation system of downhole vibration in deep wells. Adv Pet Explor Develop 10:22-26

Cun Qing H, Zheng R (2012) Robust topology engineering in multiradio multichannel wireless networks (Houston Do-U ed). IEEE Transactions on Mobile Computing, p 17

Dandage RV, Mantha SS, Rane SB, Bhoola V (2017) Analysis of interactions among barriers in project risk management. J Ind Eng Inter 14(1): 17

Devore JL (2010) Probability and statistics for engineering and the sciences, 8th edn. CENGAGE Learning, San Luis Obispo, CA

Fazaelizadeh M (2013) Real time torque and drag analysis during directional drilling (Thesis for Doctoral Degree ed) (Do Engineering, ed). Faculty of Graduate Studies, Calgary, AB

Etaje DC (2018) Identifying the optimum zone for reducing drill string vibrations. University of Calgary. 123 p. https://doi.org/10.11575 /PRISM/32358. https://prism.ucalgary.ca/handle/1880/107136

Garcia R, Calantone R (2002) A critical look at technological innovation typology and innovativeness terminology: a literature review. J Prod Innov Manag 19:23

Gillen D (2008) Benchmarking and performance measurement: the role in quality management (Vols Handbook of Logistics and SupplyChain Management) (ES Ltd, ed). School of Business and Economics, Berkeley, CA

Greenhill L, Cornejo G (1995) Critical speeds resulting from unbalance excitation of backward whirl modes. Design engineering technical conferences, ASME, Boston, MA, pp 991-1000
Kaplan RS, Cooper R (1998) Cost and effect - using integrated cost systems to drive profitability and performance. Harvard Business School Press, Boston, MA

Lapeyrose NJ (2002) Formulas for drilling, production and workover, 2nd edn (E Science, ed). Gulf Professional Publishing

McGehee DY et al (1992) The IADC roller bit classification system. IADC/SPE 23937. Society of Petroleum Engineers, Louisiana, pp 801-818

Menand S, Mills K (2017) Use of mechanical specific energy calculation in real-time to better detect vibrations and bit wear while drilling. In: AADE national technical conference and exhibition. American Association of Drilling Engineers, Houston, p 12

Offshore Technology. Cantarell Oiflied, Mexico. Retrieved 15 August, 2020, from Offshore Technology, https://www.offshore-techn ology.com/projects/cantarell/

Rahmani R, Omidvar N, Hanley C (2019)Novel drill bit technology combined with system matcher increases torque efficiency and reduces stick-slip and vibrations. In: IADC/SPE drilling conference and exhibition. Society of Petroleum Engineers, Fort Worth, $\mathrm{p} 14$

Rosellón J, Zenón E (2012) El sector de hidrocarburos en México: aspectos económicos legales y políticos. Centro de Investigación y Docencia Económicas - CIDE, División de Economía

Simmons E (1986) A technique for accurate bit programming and drilling performance optimization. In: SPE/IADC drilling conference, Dallas, TX

Stapenhurst T (2009) The benchmarking book (Butterworth-Heinemann, ed). Elsevier, Oxford

Toumi S, Beji L, Mlayeh R, Abichou A (2017) Stabilization of torsional vibration in oilwell drillstring systems. Eur J Control 35:19-27

Walzel B (2019) Mexico finding its place in offshore landscape. Hart's E\&P Energ 92(05):30-32

Weeden S (2016) Records: anniversaries indicative of technological advancement in drillbits. Hart's E\&P, pp 54-61

Yavari H, Sabah M, Khosravanian R, Wood DA (2018) Application of an adaptive neuro-fuzzy inference system and mathematical rate of penetration models to predicting drilling rate. Iran J Oil Gas Sci Technol 7:73-100

Publisher's Note Springer Nature remains neutral with regard to jurisdictional claims in published maps and institutional affiliations. 